\title{
Cultivating Innovation Capacity of Undergraduates in a Technology Commercialization Academy in Midwest America
}

Arthur L. Chlebowski ${ }^{1}$, Joshua D. McWilliams², William C. Hawkins ${ }^{3}$, and Stephanie El Tawil $^{4}$

${ }^{1}$ Department of Engineering, University of Southern Indiana, ${ }^{2}$ Department of Computer Information Systems, University of Southern Indiana, ${ }^{3}$ Departments of Biology and Kinesiology and Sport, University of Southern Indiana, and ${ }^{4}$ Growth Alliance for Greater Evansville

Cite as: Chlebowski, A.L., McWilliams, J.D., Hawkins, W.C., and El Tawil, S. (2021). Cultivating Innovation Capacity of Undergraduates in a Technology Commercialization Academy in Midwest America. Metropolitan Universities, 32(2), 3-26. DOI: 10.18060/23931

This is an open access article distributed under the terms of the Creative Commons Attribution License.

Editor: Valerie L. Holton, Ph.D.

\section{Abstract}

The Technology Commercialization Academy (TCA) was launched to promote the identification, assessment, and exploitation of economically viable innovations by undergraduates and retain those graduates in the southwest Indiana region. Further, as part of the I-69 Innovation Corridor initiative, the TCA was part of increasing the regional Innovation Index score $20 \%$ by 2025. Through the seven years of implementation, the program has determined that there is a crucial tool set that is necessary for new graduates entering industry, including instilling that innovation is a balance; innovation is agile; innovation must fail, pivot, and focus quickly; and lastly the program must realize its capabilities, be diverse in thought, and recognize that the personnel are key. By instilling these practices in the participants, using available programmatic information and surveys, $100 \%$ of job seekers post-graduation were employed within six months, $9 \%$ began their own startup from the program, and $64 \%$ of these high impact graduates stayed in southwest Indiana. Overall, the TCA program structure has shifted to demand side iterative processes that create long-tail value for the region and made the participants attractive hires who are keenly aware of practices to move from opportunity to execution.

Keywords: entrepreneurship, frameworks, sprint, feasibility 


\section{Introduction}

When a university is part of a regional innovation ecosystem, it generally interacts in one or both of the following capacities. First, the university offers specialized program outside of standard university format aimed at bridging the entrepreneurial gap and/or offering entrepreneurial education (either through undergraduate, graduate entrepreneurial programs, or mentorship). Second, the university serves as a conduit for these activities by providing access to technology, either through technology transfer, research, equipment, and/or infrastructure, in addition to subject matter expertise via faculty, staff, and/or research personnel (Bezerra et al., 2017). The development and exploitation of these capacities, when coupled with community collaboration, allow regional growth (Johnson Jr, 2014).

Specialized programs, accelerators, or incubators are solely aimed at the development of entrepreneurial ideas and progression of the business. Documentation of the creation of these programs is readily available in terms of facilities, layout, infrastructure, and workforce (Jurkowski \& Kerr, 2010; Thompson, 2012). The standard accelerator and incubator aid potential companies in moving their idea forward via access to investors, technology experts, and/or mentors in an effort to develop a robust pipeline of talent and shovel-ready ventures (Biemiller, 2018; Custer, 2015; Johnson Jr, 2014; Klugh \& Williams, 2017; Ochs et al., 2001; Tekula \& Jhamb, 2015; Woods et al., 2016). Different methodologies are used to enhance and improve the business proposition of the participants including, but not limited to: mentorship, networking/investors, "the student becomes the teacher," focus on leadership, expedited MBA, partnership with local industry, or workshops by experts (Bogomolny, 2005; Garcia \& Ustymchuk, 2020; Gilbert, 2010).

Meanwhile, the standard undergraduate entrepreneurial experience encompasses coursework aimed at teaching supply-side ideation through experience in the development of a business plan or business model canvas, and culminating in articulation via refined pitch. Developed from the perspective of pedagogy (Collet \& Wyatt, 2005; Hanna, 2013; Heinrich et al., 2018), once that entrepreneurial student has reached the culmination of their educational experience, they have a set of tools that are useful for themselves, prospective employers, or for advancing their prospective innovations. Very few undergraduates pursue the idea(s) developed as part of the curriculum or, if pursued, the ideas are found so underdeveloped that they are unable to enter the specialized programs (Bezerra et al., 2017).

This creates a gap in the undergraduate innovation puzzle. While it can be easy to find the infrastructure, personnel, and technology to grow an idea, there has traditionally been a valueproposition deficit for large portions of the student population to justify dedicated time to these efforts. All too often, current undergraduate programs are designed for the individual that already has an entrepreneurial mindset and exclude a large population of aspiring young entrepreneurs 
who may not be matriculating through a business school curriculum. Further, the puzzle, as currently configured, assumes a robust pipeline of mature talent and ideas before being provided access to a launchpad to success via incubators and accelerators with access to capital, mentorship, and space. Bezerra et al. reviews the innovation space for the young entrepreneur and defines four main characteristics that need improvement for their success (2017), including: practical activities as a way to develop new business ideas; centrality of the incubation process; lack of credibility and resources; and difficulty in maintain a long-term relationship with the university.

This paper discusses the Technology Commercialization Academy (TCA) program, which was designed to take approximately 16 students from all disciplines represented on the University of Southern Indiana (USI) campus and provide them the tools for discovering and capitalizing on opportunities. Participants did this via inspirational subject matter made available through the NSWC Crane Technology Transfer (T2) office, local entities, or newly developed personal ventures via a paid 12-week student fellowship culminating in pitch events. The paper continues by discussing the Southwest Indiana regional background, methodologies, results and findings, the discussion of findings, and a conclusion.

\section{Southwest Indiana Regional Background}

Southwest Indiana has unique geographic positioning that allows for an unmatched distribution network: a central location provides access to $75 \%$ of the nation's population within a one day drive; twenty-two linehaul railroads provide intermodal connectivity to the east and west coasts; and, easy access to international waters via the seventh largest inland port in the United States (Economic Development Coalition of Southwest Indiana, 2019). With the geographic advantages, the southwest region has been a mainstay for manufacturing processes but has suffered at attracting and retaining high impact companies. To understand a region's impact, the Innovation Index can assess a region's innovation capacity and output (Figure 1). The southwest region of Indiana had a decrease in high tech jobs from 1997-2009 in comparison to the rest of Indiana and the United States, while having a larger ratio of job growth to population growth. The number of patents produced by this region is less than half the average of the United States during that time period (Innovation 2.0, 2019).

Evansville also ranks 179 th while being the 232nd most populous city in the country. Analyzing the data further (Figure 2), Evansville is successful in areas that are defined by the presence of strong legacy businesses and education (13th and 153rd respectively), but fares poorly in the creation of new entities, knowledge creation and technology diffusion, and access to venture capital (301st, 354th, and 245th respectively) (Innovation 2.0, 2019). 
Figure 1. Innovation Index comparison ratios 1997- 2008/09. Custom region defined as southwest Indiana.
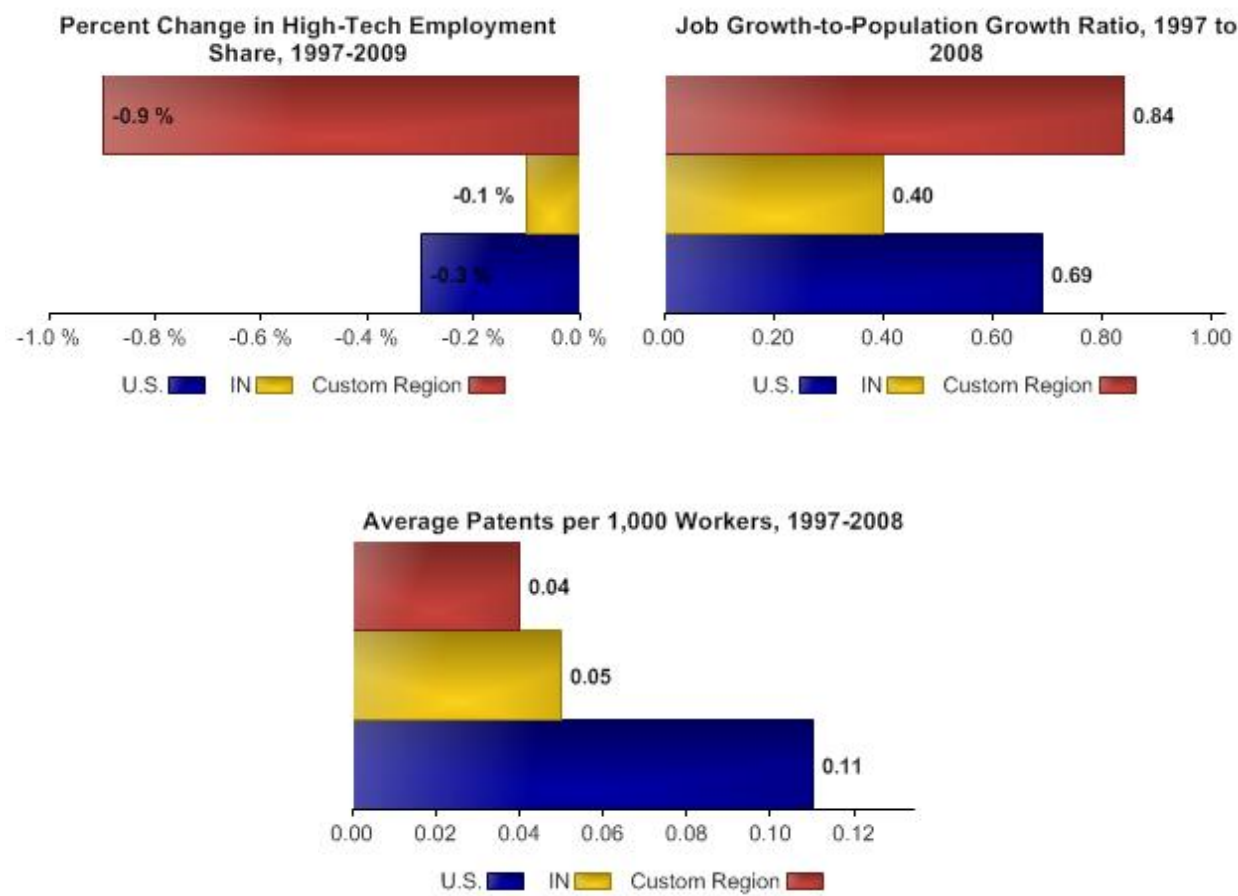

Figure 2. Innovation Index Ranking - Midwest Towns/Cities and U.S.-wide Innovation Centers

\begin{tabular}{|c|c|c|c|c|c|c|c|c|c|c|}
\hline Metro Area Index Value & $\begin{array}{l}\text { Evansville, IN } \\
\text { (Metro) }\end{array}$ & $\begin{array}{l}\text { Fort Wayne, IN } \\
\text { (Metro) }\end{array}$ & $\begin{array}{l}\text { South Bend, IN } \\
\text { (Metro) }\end{array}$ & $\begin{array}{l}\text { Dayton, } \mathrm{OH} \\
\text { (Metro) }\end{array}$ & $\begin{array}{l}\text { Peoria, IL } \\
\text { (Metro) }\end{array}$ & $\begin{array}{l}\text { Lansing, MI } \\
\text { (Metro) }\end{array}$ & $\begin{array}{l}\text { Columbia, MO } \\
\text { (Metro) }\end{array}$ & $\begin{array}{c}\text { Chicago, IL } \\
\text { (Metro) }\end{array}$ & $\begin{array}{l}\text { Boston, MA } \\
\text { (Metro) }\end{array}$ & $\begin{array}{c}\text { San Francisco, CA } \\
\text { (Metro) }\end{array}$ \\
\hline Innovation Index & 179 & 224 & 274 & 189 & 111 & 173 & 80 & 62 & 13 & 1 \\
\hline - Human Capital and Knowledge Creation Index & 284 & 171 & 227 & 82 & 142 & 64 & 51 & 61 & 11 & 7 \\
\hline Educational Attainment & 245 & 220 & 277 & 140 & 143 & 8 & 33 & 150 & 67 & 64 \\
\hline Knowledge Creation and Technology Diffusion & 354 & 117 & 191 & 67 & 189 & 218 & 227 & 20 & 9 & 1 \\
\hline STEM Education and Occupations & 153 & 129 & 119 & 41 & 93 & 82 & 68 & 67 & 11 & 20 \\
\hline - Business Dynamics Index & 248 & 210 & 342 & 199 & 125 & 137 & 107 & 65 & 8 & 4 \\
\hline Establishment Formation & 301 & 306 & 335 & 225 & 282 & 266 & 177 & 61 & 129 & 10 \\
\hline Establishment Dynamics & 137 & 104 & 337 & 240 & 64 & 264 & 90 & 190 & 54 & 28 \\
\hline Venture Capital Dollar Measures & 227 & 206 & 238 & 182 & 126 & 113 & 138 & 61 & 4 & 2 \\
\hline Venture Capital Count Measures & 245 & 232 & 237 & 237 & 141 & 66 & 148 & 57 & 6 & 2 \\
\hline - Business Profile Index & 13 & 173 & 149 & 156 & 282 & 219 & 298 & 77 & 40 & 49 \\
\hline Foreign Direct Investment Attractiveness & 50 & 127 & 226 & 90 & 211 & 86 & 236 & 139 & 93 & 143 \\
\hline Connectivity & 64 & 218 & 99 & 266 & 229 & 155 & 329 & 91 & 38 & 37 \\
\hline Dynamic Industry Profile & 112 & 174 & 284 & 173 & 261 & 311 & 167 & 14 & 18 & 17 \\
\hline Proprietorship & 66 & 187 & 138 & 323 & 367 & 353 & 366 & 193 & 172 & 138 \\
\hline - Employment \& Productivity Index & 202 & 250 & 128 & 302 & 76 & 305 & 107 & 143 & 153 & 28 \\
\hline Industry Performance & 182 & 114 & 177 & 304 & 297 & 322 & 213 & 247 & 309 & 142 \\
\hline Gross Domestic Product & 101 & 252 & 160 & 202 & 17 & 253 & 232 & 85 & 62 & 38 \\
\hline Patents & 103 & 169 & 98 & 138 & 64 & 129 & 49 & 58 & 54 & 38 \\
\hline - Economic Well Being Index & 187 & 274 & 317 & 231 & 84 & 234 & 66 & 281 & 92 & 95 \\
\hline compensation & 142 & 323 & 251 & 151 & 44 & 230 & 58 & 310 & 119 & 90 \\
\hline
\end{tabular}

Due to these data points Growth Alliance for Greater Evansville's (GAGE) mission is to drive and support economic development activities. As part of these activities, partners were sought to support the essential technology transfer component required to incite high technology startups. Partnership Intermediary Agreements were formed between the Naval Surface Warfare Center, Crane Division (NSWC Crane), USI, and GAGE. NSWC Crane (located in southern Indiana) provides technical engineering solutions and total lifecycle leadership for many of the systems

(C) The Author 2021. Published by the Coalition of Urban and Metropolitan Universities. www.cumuonline.org Metropolitan Universities | DOI 10.18060/23931 | August 3, 2021 
that protect and enable the warfighter, and this intellectual property (IP) portfolio is available for development of commercial technology. With the completion of Interstate 69 from Evansville to Crane, Indiana, a prioritization of activity was strategically conceived resulting in the formation of the I-69 Innovation Corridor (GAGE, 2019). The purpose of the corridor initiative was to increase the regional Innovation Index score $20 \%$ by 2025 through the development of Brainpower, Innovation and Entrepreneurship Networks, Quality, Connected Places, Branding Experiences, and Civic Collaboration. Brainpower starts with a sound education and imagination. Entrepreneurial educators can generate 21 st century brainpower with skills to support globally competitive businesses. Innovation and Entrepreneurship Networks create business development networks (clusters, entrepreneurial support, venture capital, mentors) capable of converting brainpower into wealth through innovation and entrepreneurship endeavors. Quality and Connected Places entices mobile people and companies that are innovative to locate in places with high quality of life and remain connected to the rest of the world. Branding Experiences define the region's story by depicting to young professionals that the region has a future that is vibrant and exciting. Lastly, Civic Collaboration produces leaders that are skilled in the art and discipline of collaboration.

USI acted as the educational partner and secured funding to support activities associated with Brainpower, Quality, Connected Places, and Innovation and Entrepreneurship Networks. Through the partnership with GAGE, this resulted in the development of several cooperative undertakings. Tech on Tap is a community-led program that fosters innovation by promoting collision, connection, and collaboration through hosted events. Tour of Opportunity incorporates a daylong event that allows middle school students the opportunity to view local career prospects first-hand, encouraging early talent retention and pathfinding. The Technology Commercialization Academy planted the seed of innovation discovery in USI students who might not otherwise have access to the region's entrepreneurial resources.

\section{Methodology}

\section{General Setup of Program}

The length of the TCA program has varied but has ultimately settled at 12 weeks long, with students working 24-25 hours per week, which equates to 7.5 full 40-hour work weeks. Students are initially taught entrepreneurial and innovation practices towards ideation and business feasibility. Ideas are then assessed using different frameworks, as discussed in later sections, throughout the commercialization process. If the product faltered, the students pivoted to assess other ideas and began the process of commercial risk mitigation again with the new idea. At the end of the TCA, pitch events are scheduled. The first is a public pitch event in which participants present the opportunities discovered, the market research they have performed to validate the commercial viability of those opportunities, and present a proof of concept. The result of this 
pitch is to curate a collision between student, mentor, or local entity resulting in the formation of new entities and collaboration with individuals or entities with access to capital. A second pitch is conducted with NSWC Crane personnel, to showcase to the inventors of the military technology how their concepts sparked innovation and inspiration for the potential commercial applications.

\section{Decision Making for Programmatic Changes}

Programs were assessed yearly regarding the cumulative content production from the previous year using qualitative analyses of overall impact to the undergraduate student experience, utility of NSWC Crane intellectual property, and student professional readiness. This assessment was conducted via observations collected during phases of the program as participants completed activities and advanced potential innovations. Further, the program initially focused on quantity of supply-side innovation from NSWC IP and development of the commercial case via business model canvas. Later iterations of the programming focused on enhanced quality via the introduction of new tools to emphasize product-market fit and demand-side customer-focused feedback. Therefore, content and tools adjusted from year-to-year to fit the focus of the program.

\section{Student Selection}

The application process for participant selection in the TCA program is open to all students across the USI campus. Students interested in participating in the next summer's cohort must fill out an application (Supplemental Figure 1) with several questions pertaining to their interests and goals. A student does not need to have entrepreneurial startup goals to be selected, but an interest in expanding their comprehension is crucial to success, as there are stages that require prototyping, business development, critical thinking, or problem-solving. During the assessment of applications, candidates were evaluated via the following criteria: professionalism and likelihood of making a positive contribution to the program as currently defined; ability to find gainful employment immediately following the completion of the program/their degree; and assessment of ability to provide unique insights during the creative process. A Likert Scale (0 low -5 high) was used by the instructors and coordinators of the program to rank applicants. An average of the rankings was taken, and the top 16 students were asked to join the program, while the next 4 students were selected as alternates.

Instructors

The TCA program used USI faculty and staff from multiple disciplines to guide students through the ideation, feasibility, and commercialization processes. Instructors were selected based on professional and personal experiences with innovative technologies, small business formation, IP knowledge, and a passion for entrepreneurship. 


\section{Mentors}

The TCA program used mentors from inside and outside of the academic setting for their expertise in a given area. Depending on the portion of the program, a mentor was established and used to aid the students in that specific phase of the program. Mentor relationships were leveraged to gain resources with field experience in the development of the product-market fit, prototyping, and business development to aid TCA participants in the refinement of the prospective opportunity.

\section{Technology Selection}

Problem identification began by using IP from NSWC Crane as a method to transfer military technology or ideas to civilian commercialization opportunities. The instructors and coordinator of the program identified and selected the initial patented technologies. This was conducted by assessing the claims of the IP and making selection based on how developed the IP was from conceptual to deployed, as well as capabilities to prototype, and lastly anticipated student comprehension. Additional sources of potential innovation discovery were identified as participants brought personal interests and local small businesses/entrepreneurs requested to participate.

\section{Talent Development}

As retention of Brainpower is a top objective within the TCA, the first week of the program focused on talent development and career pathfinding. The students were prompted to identify their perfect occupation in the southwest Indiana region and construct a professional development plan to achieve that role. Additionally, students updated resumes, completed personality and work preference assessments, and individually connected with professionals in their desired occupation. The respective professionals were then invited to the culminating pitch event with the initiative and aid in enhancing the talent pipeline for regional employers.

\section{Ideation Framework}

To begin ideation, students were introduced to high-level components of the NSWC Crane IP technology, its direct military application, and the problem it attempts to resolve. The students were encouraged to ask open-ended questions in this discovery portion done by visiting the location where the technology is currently deployed or visiting with the inventor or entrepreneur. Following the introduction to the problem, students began identifying various realms of application for the technology in a commercial space, i.e. students created divergent lists of other direct and indirect uses of the IP. After compiling a massive list of ideas with limited constraints, the students converged on their top areas of interest. Those focal points were then assessed based 
on observable problems within that commercial domain, followed by solutions-oriented ideation exercises. Through this exercise, the TCA students retained the concept that every product must solve a problem for the consumer, as well as divergence and convergence ideation techniques essential to iterative opportunity discovery. Ideation is done via several different methods, and our program focused on methods developed by Celuch et al. (2014). The goal of this concept creation is to develop as many ideas as possible in the divergence phase using random stimuli and then converge by allowing participants to select only a few possible feasible solutions. The stimuli include, but are not limited to, imagery, sounds, and phrases. These stimuli provoke ideas, and participants note these solutions. Students were coached that no idea is too grand or impossible, and each captured idea stimulates thought and further ideation from the remaining participants.

\section{Feasibility Framework}

Once the initial ideation session was complete, students began the process of determining which ideas to develop and assess for business analysis. Feasibility began based on the expertise of the students and mentors, as well as local resource availability, including a prototyping center and design software. Students select their top 3-4 ideas to conduct a careful examination on feasibility. Idea selection was done initially by a majority vote of the group. Through feasibility evaluation, students discovered if the idea had merit and proceed forward, if not, they returned to their remaining top ideas and restarted the process. Feasibility was categorized by two capabilities: (a) is there a market for the problem-solving idea?; (b) and can a technical prototype be developed to attain customer feedback? In initial TCAs this was done ad hoc, with students determining feasibility by their own set of parameters. In later TCAs, the Feasibility Idea Test (FiTest), a more formal documentation method, developed by USI faculty, that provided a first blush business case analysis was implemented. Technical feasibility used the university's Applied Engineering Center (AEC) and available engineering faculty for development of a functional prototype, or initial pretotype (nonfunctional façade). The market and technical feasibility analysis was repeated using customer feedback as validation to proceed or restart the process. Students went out to potential customers and received feedback on whether the problem was understood, and the solution was valuable. Discovery of market validation required qualitative interviewing techniques intended to map out the customer experience, thus framing the set of problems typically experienced by the potential customer more thoroughly before providing a suggested solution. If market viability was acceptable with present consumer demand, the students repeated this iterative process until all feasibility questions were answered, and the prototype had enough functionality to promote its innovative purpose. 


\section{Business Model Canvas}

Following market and technical feasibility, students were asked to develop a business case for their product. Generally started while conducting feasibility, the business model canvas (Supplemental Figure 2) is used to describe and build a business case by proposing and testing a series of hypotheses for each of nine components (Osterwalder \& Pigneur, 2010). This allows the student to quickly propose, test, and validate the potential new venture via the visual layout to develop their pitch.

\section{Design Sprint Framework}

The design sprint developed by Google Ventures was incorporated into the TCA curriculum to help develop more viable ideas through facilitated methodologies (Knapp et al., 2016). The sprint method created a more formal method to ascertain answers to questions on potential product ideas. Students could use this process whenever a question came up as a quick method to resolve and proceed with commercialization. The sprint process facilitates product development in a highly detailed, concise, and structured format that results in confident decision and clearer analysis. The design sprint is presented as a five-day process and covers problem definition, ideation, prototyping, and initial customer validation. If an idea is successful through this process, it could transition to feasibility analysis via the rigorous FiTest.

Jobs to Be Done Framework

Customer validation is a critical point in the commercialization process as it determines the viability of the idea and dictates the direction or progress of the proposed solution. Jobs to Be Done (JTBD), a qualitative interviewing and customer journey mapping technique, was utilized during the last three TCAs to help students understand the solutions and process by which consumers currently solve the problem. JTBD explores the qualitative analysis of consumer purchasing behaviors through assessment of the explicit journey the customer takes to make a decision. Through the development and implementation of interviewing techniques, participants explored the emotional and chronological journey through the lens of a recent potential customer's experience. This formalizes the customer interaction as a result of insights from a sample of those who had already made decisions on existing solutions, aiding in the evaluation of feasibility, and determining the true demand of the customer (Christensen et al., 2005). TCA students were introduced to this methodology very early in the program in preparation for interviewing the original inventors of the NSWC Crane IP. This created an inquisitive atmosphere in the general workspace as the JTBD format constructs a personal interaction between participants and encourages the students to remain quizzical throughout the duration of the program.

(C) The Author 2021. Published by the Coalition of Urban and Metropolitan Universities. www.cumuonline.org 


\section{Results and Findings}

The initial offering (2012-2014) of the TCA was designed to mirror the curriculum of the USI Romain College of Business' AACSB accredited entrepreneurship minor. The program was five weeks in duration and provided a stipend for students participating in the program (Figure 3). During the first week, the TCA students were introduced to the program and visited NSWC Crane to learn about the IP selected for mining.

Figure 3. Initial TCA Offering
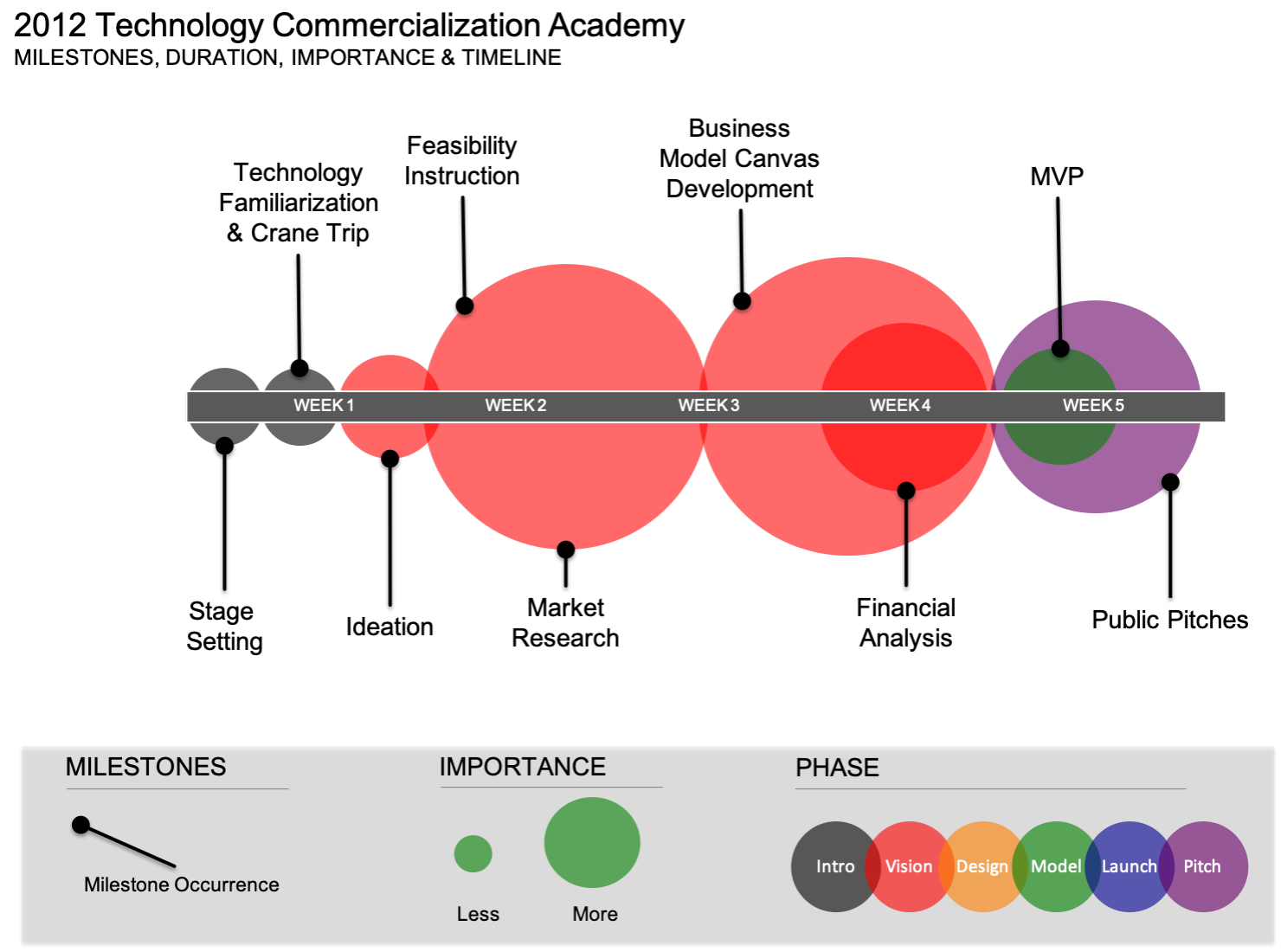

Following IP identification, ideation commenced obtaining commercial opportunities. The second week focused on market validation of a converged set of opportunities with the third and fourth weeks being devoted to the development of the remainder of the business model via use of the business model canvas, with a small amount of time devoted to the development of a minimum viable product (MVP). During the final week, students developed and practiced a pitch which was delivered on campus and open to the public. 
Mentors from outside entities were used to supplement expertise towards the business model canvas and pitch development. This approach generally worked but it was determined to be too short in duration at five weeks and university regulation forced a student labor cap at a maximum of 28 hours per week. As a result, the program was extended to an 8.5-week full-time equivalent (FTE) model, comprised of a 12-week duration with 28 hours per week. Further, at the culmination of its first year, based on the output created by the students, a more inclusive program was desired and applications were opened up to the entire campus.

TCAs 2015 and 2016 expanded on tools and time that the students used to develop their ideas into viable product offerings. Students now had 28 hours a week over a 12-week period. Ideation was still crucial in the initial stage with visits to NSWC Crane for technical understanding. Focus was brought toward increased customer validation through feasibility with a conceptual design and prototype. If an idea did not pass feasibility, the students revisited the idea or pivoted and restarted the feasibility process. The end of the program was marked by market validation for a few weeks and then pitch preparation in the final two weeks of the program. Students pitched ideas that were brought through the feasibility stage and noted where they may have failed in the process, or where they stand after the program, while encouraging feedback from the public audience.

To renew student excitement and bolster local impact, TCA 2017 highlighted interaction with clients, i.e. local businesses combined with IP from NSWC Crane. Second, design sprints (Google Sprints) were introduced to streamline student determination if the implementation of IP or other ideas had client merit and customer validation. A student team began by running a sprint on the problem posed by the client, and if initial customer validation was successful in the sprint, the teams would then transition to formal feasibility and prototyping, and finally to completion of the business model, if time allowed. This process allowed the students to fail and pivot quickly. As Woods et al., (2016) discussed, the students could then "Invest in, learn from, promote, and celebrate bite-sized successes. Then repeat" (p. 99). More time was spent on teaching tools to the students in the 2017 TCA to ensure students were well trained in development practices to benefit each student throughout their academic and professional careers. 
Figure 4. Culminating TCA Program Timeline

2019 Technology Commercialization Academy

MILESTONES, DURATION, IMPORTANCE \& TIMELINE
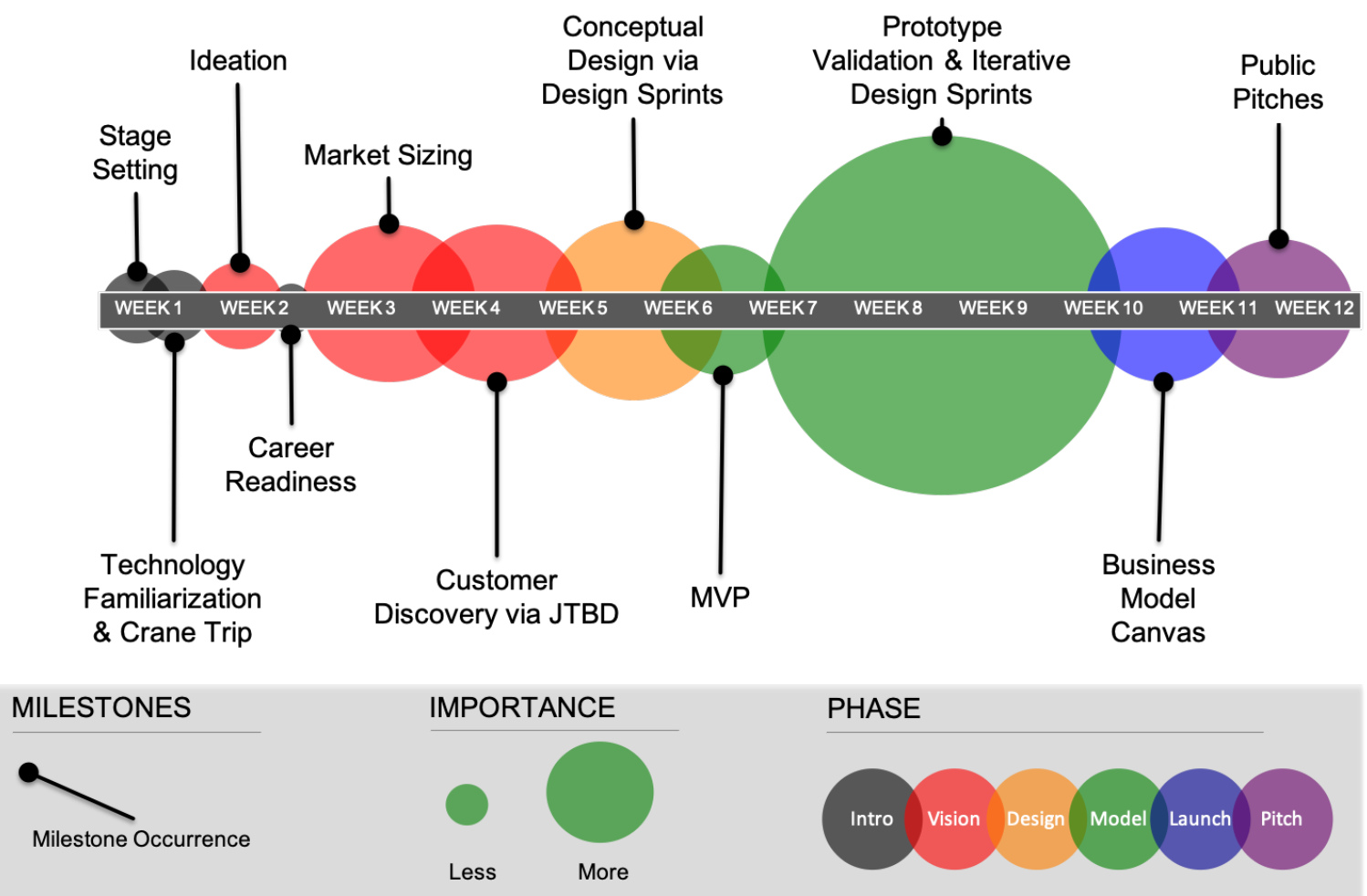

Table 1. TCA Impact on Young Entrepreneur Characteristics

\begin{tabular}{|l|l|}
\hline Characteristics (Bezerra et al., 2017) & TCA Program Implementations \\
\hline Practical activities as a way to develop new business & 2012 - Usage of course developed ideation process by \\
ideas & Celuch et al.; Interaction with NSWC Crane for IP \\
\hline Centrality of the incubation process & 2012 - Crane IP Inventor interaction \\
& 2015 - Fit Test aimed at Supply Side feedback \\
& 2017 - JTBD Demand Side innovation; shift to self- \\
& sustaining unstructured use of toolset. \\
\hline Lack of credibility and resources & 2014 - Program marketed to entire campus \\
& 2015 - Program moves to Innovation Pointe; \\
& Prototyping added. \\
& 2017 - Sprint Process; Program Recognition \\
\hline Difficulty in maintaining a long-term relationship with & $2015-$ Access to the USI Applied Engineering Center \\
the university & \& Center for Applied Research \\
\hline
\end{tabular}

(C) The Author 2021. Published by the Coalition of Urban and Metropolitan Universities. www.cumuonline.org Metropolitan Universities | DOI 10.18060/23931 | August 3, 2021 
TCA 2018 and 2019 (Figure 4) included increased professional development components and introduced the Jobs to Be Done (JTBD) toolset to the students. Professional development components were introduced to connect students with regional employers to intentionally optimize the talent pipeline. Students used the JTBD tool in conjunction with all the other previous tools, bringing focus to the problem the customer was trying to solve rather than general customer approval on supply-side innovations. Further, with student feedback on the rigidity of TCA 2017, a more informal TCA 2018 was conducted. These TCAs focused tools toward start of program. This permitted students to work at their pace, allowing them to take ownership of their idea rather than feeling pressured working on another company's idea or another student's passion project. However, the self-guided pace in 2018 resulted in an overall decrease of momentum, which impacted business case completion. TCA $2019 \mathrm{kept}$ the same layout as TCA 2018 with the goal of balancing the freedom experienced in TCA 2018 and the structure that generated more output from the previous years. This final programmatic layout (Figure 4) brought forward a value-add toolset with focus on customer centric validation and improved on the initial offering seven years prior (Figure 3).

\section{Discussion of Findings}

The TCA was originally developed as a method to aid in the translation of military IP into commercial IP, and through regular assessment a set of key features began to emerge as successes to the TCA program. An analysis conducted on reviewing the impactful characteristics of young entrepreneurs found that there are four characteristics needed for student start-ups to take the next step forward (Bezerra et al., 2017). During the maturation of the TCA program, which occurred simultaneously to this analysis, the authors independently validated need in the characteristics identified by Bazerra et al. As a result of the intentional qualitative assessment of the program and subsequent iterations as described above, the TCA developed solutions to those characteristics (Table 1).

In total, the TCA has pitched approximately 20-30 ideas over the seven-year program, in addition to the hundreds of ideas that were initially thought of but not continued due to feasibility issues. The ideas that had enough technical and market feasibility were pitched at an end of program public event (Table 2) and ranged from three ideas to a maximum of nine yearly. In total, 121 students completed the program and through the 2017 cohort, data were collected on students after their TCA experience (Table 3). Of those 89 participants that have completed the program, $100 \%$ of the students that shared data had job placement within six months, compared to the school average placement rate from 2012-2017 of 85.1\% (OPRA, 2018). Of those students in the workforce, rates of $64 \%$ and $71 \%$ (OPRA, 2018) are observed for participants who stayed in southwest Indiana and university data of those within 70 miles of campus, respectively. Additionally, noted within the collected data from the TCA, nine participants created their own start-up companies. 
Table 1. Summary of Idea Creation through TCAs

\begin{tabular}{|c|c|c|c|}
\hline $\begin{array}{c}\text { Year } \\
\text { (\# of Ideas) }\end{array}$ & List of Ideas & $\begin{array}{c}\underline{\text { Year }} \\
\text { (\# of Ideas) }\end{array}$ & $\underline{\text { List of Ideas }}$ \\
\hline $\begin{array}{l}2012 \\
(3)\end{array}$ & $\begin{array}{l}\text { - Bedsore Reduction Smart Pad } \\
\text { - Student Centered Course } \\
\text { - Scheduling } \\
\text { - Smart Target }\end{array}$ & $\begin{array}{l}2016 \\
(5)\end{array}$ & $\begin{array}{l}\text { - Exceed Group Communication } \\
\text { - Marshalling Gloves for Airports } \\
\text { - SPARA all-in-one household energy } \\
\text { conservation } \\
\text { - Kitera Marketing Sprint and Design } \\
\text { - EAGLEi }\end{array}$ \\
\hline $\begin{array}{l}2013 \\
(4)\end{array}$ & $\begin{array}{l}\text { - Eband Theme Park } \\
\text { - Tracking } \\
\text { - Real Time inventory } \\
\text { - Tracking System for Stores } \\
\text { - Instant Coupon using } \\
\text { - Geofencing } \\
\text { - Cell phone identification during } \\
\text { emergency or disaster }\end{array}$ & $\begin{array}{l}2017 \\
(7)\end{array}$ & $\begin{array}{l}\text { - Boredom Busters Sprint/App } \\
\text { - 5D Analytics Sprint } \\
\text { - Motivating Systems feasibility/market } \\
\text { - 2Hook4: pitch and sprint } \\
\text { - TCA Branding/ Marketing Sprint } \\
\text { - DT Application in Engineering } \\
\text { - DT Application in Medicine }\end{array}$ \\
\hline $\begin{array}{l}2014 \\
(9)\end{array}$ & $\begin{array}{ll}\text { - 3-D scanner } & \text { - Stop Tops } \\
\text { - PUR-Wheel } & \text { - Smart Roof } \\
\text { - Physical } & \text { - Foundation } \\
\text { Therapy } & \text { Damage Detection } \\
\text { Tracker } & \text { - IntelliTarget } \\
\text { - Tread Condition } & \text { - Clever Cubes } \\
\text { Alert System } & \end{array}$ & $\begin{array}{l}2018 \\
(4)\end{array}$ & $\begin{array}{l}\text { - MAGIC Glasses } \\
\text { - Drone Catcher } \\
\text { - Grill Regulator } \\
\text { - Nature Nodes }\end{array}$ \\
\hline $\begin{array}{l}2015 \\
(5)\end{array}$ & $\begin{array}{l}\text { - EZ Spooler } \\
\text { - LOCify } \\
\text { - Hose Helper } \\
\text { - Volver Reel System } \\
\text { - Motor Development Arm }\end{array}$ & $\begin{array}{l}2019 \\
(7)\end{array}$ & $\begin{array}{l}\text { - UR Trash } \\
\text { - Curio } \\
\text { - Riverside Cinema } \\
\text { - Filetor } \\
\text { - Involve Life } \\
\text { - Wave Noise Cancelling System } \\
\text { - Screagle Card }\end{array}$ \\
\hline
\end{tabular}

Anecdotally, past participants stated that during interviews with their future employers, a major discussion point was their participation in and skillsets developed throughout the TCA program. In an effort to increase the innovation index of the surrounding region, the $100 \%$ placement of participants is crucial to the success of the regional brainpower and intellectual capital initiatives developed at grant inception. As the program is open to all students, and those students who submit an application are pursuing advancement of their understanding and interest in innovation, the students who decide to become participants can be considered some of the university's most ambitious students. Even so, participants have traditionally been top students both academically and through campus involvement, as a result of the evaluation criteria utilized. Even though the program has a lower rate of retention to southwest Indiana relative to all USI 
graduates $(64 \%$ compared to $71 \%)$, these participants remain in the region, promoting its growth rather than moving to traditionally rich innovation magnetitic areas of the country. Though the program aimed to advance a participant's innovation capacity, as opposed to the creation of startups, it is important to note that $\sim 10 \%$ of the graduates have taken it upon themselves to start a business.

Table 2. Participant Data after TCA (Through 2017 TCA cohort)

\begin{tabular}{|c|c|c|c|c|c|c}
\hline \multirow{2}{*}{$\begin{array}{c}\text { Participant Outcome } \\
\text { (Collected Data) }\end{array}$} & \multicolumn{2}{|c|}{ Job Placement } & \multicolumn{2}{c|}{ Pursuing Master's Degree } & \multicolumn{2}{c}{ Located in Southwest Indiana } \\
\cline { 2 - 7 } & Count & Percent & Count & Percent & Count & Percent \\
\hline Yes & 54 & $100 \%$ & 9 & $16 \%$ & 35 & $64 \%$ \\
\hline No & 0 & $0 \%$ & 46 & $84 \%$ & 20 & $36 \%$ \\
\hline Overall Data (Based on 89 Participants) \\
\hline Participant Data Collected & 54 & $60.70 \%$ & 55 & $61.80 \%$ & 55 & $61.80 \%$ \\
\hline Unknown & 16 & $18.00 \%$ & 15 & $16.90 \%$ & 15 & $16.90 \%$ \\
\hline Student & 19 & $21.30 \%$ & 19 & $21.30 \%$ & 19 & $21.30 \%$
\end{tabular}

Throughout the program, the most critical observation has been the correlation between success and the student's buy-in that the tools are useful and necessary throughout their careers. This connection is the reason why the program has adapted iteratively from 2012 (Figure 3) to 2017 (Figure 4). During the program, the participants do not directly see the benefit of the TCA tools, at times expressing frustration with the non-academic techniques. However, once the program is completed and a successful pitch has been presented, the students are better able to view the usability of these tools in the future, and how the tools shaped the results of their TCA experience, expressed via their statements related to job placement being driven by their participation in the program.

The TCA program was purpose-built to be adaptive to changing landscapes in cohort profile, available IP, and new innovation discovery techniques. Through the adaptations of the program, the structure was fine-tuned to maximize impact for students and community. First, the program had to realize its capabilities, and it was quickly identified that multi-disciplinary inclusive interaction is crucial, as were the roles of mentors and external participants. Once the program adopted these considerations, participants received both an enhanced understanding of technological theory and realization of technology commercial feasibility. It was noted that while knowledge of equipment, and science is generally crucial to prototype functionality, vision and creativity are required to bring a truly innovative opportunity to the table. Expansion of the opportunity to explore entrepreneurship across a university community brings diverse ideas and thought, in turn enhancing the student experience, programmatic output, and long-tail economic impact.

(C) The Author 2021. Published by the Coalition of Urban and Metropolitan Universities. www.cumuonline.org Metropolitan Universities | DOI 10.18060/23931 | August 3, 2021 
Adaptions from the initial undertaking of the TCA found success in developing student understanding that failure occurs, and in order to maximize value from those failures it is important to fail quickly to identify whether to kill, pivot, or focus effort. The five-day sprint was introduced to push the participants to not loiter with an idea and the inclusion of the sprint forced them to explore an idea, develop a testable prototype, focus on customer feedback, and make the decision on whether or not to move forward. This provided enhanced value, as it does in the context of software development, by providing a mechanism to timebox the creation of something tangible and testable.

Using this iterative process, the 2016 and 2017 cohorts attempted to have more direct impact on the external community by providing innovation as a service to external clients, which required a more structured schedule and coordination with local businesses. These cohorts were successful in creating ideas and delivering products for these businesses, but the impact on the student was missed. They learned the tools, but were unable to see how the tools work towards an idea that resonated, and therefore did not personally connect to the problems or the solutions addressing the needs of these external entities.

The 2018 and 2019 cohorts prioritized ideation and problem solving that is relevant to the participants and generates passion and enthusiasm. Since the ideas originated from the student, they had complete buy-in on the importance of the problem they attempted to resolve. This resulted in a more thought-provoking and rewarding experience for the students, though the immediate impact on the regional community diminished. Following several iterations of the program it was determined that this promoted intermediate and long-term return for the community as a result of equipping these cohorts with the tools necessary to identify and exploit economic opportunities for either themselves or their employers upon graduation.

In review of the seven-year program, it was found that participants needed to learn balance and agility. Traditional entrepreneurship programs deliver on supply-side innovations, which are often those with high potential but in search of a customer. The introduction of Jobs to Be Done, as well as the sprint processes brought focus to the consumer. The authors noted that students can have trouble accepting that their idea is not the right idea; providing a framework to hear directly from potential customers has immense value in validating their idea or providing potential pivot opportunities. Similarly, solely focusing solely on demand-side innovation places limitations on ideation and restricts impact of potential outcomes. Participants and coordinators have to be agile in the use of different frameworks to help understand prospective problems or needs. Mentors have to be open to other frameworks to aid in a guiding participant's prospective venture. While a mentor-sponsored framework may be beneficial, other processes are available to formulate, test, and move an idea forward, the authors found it critical for mentors and participants to have many tools in their toolbox from which to gain insight. 
As a direct result of the TCA, the Rural Indiana Technology Commercialization Initiative was started and other national federal labs have begun their own commercialization academies (Air force Research Laboratory, 2015). The program has been recognized nationally, including commendation as a significant contributor to the successful relationship with NSWC Crane during a briefing hosted by the Office of Vice President, Mike Pence (Luttrell, 2017). As a program initiated through grant funding, USI decided at the culmination of the grant to continue the program.

\section{Conclusion}

By objective measure the TCA program has been considered a success in providing new capabilities to USI graduates and subsequently the region, each graduate of the TCA program is equipped with skillsets that prepare them to constantly look for opportunity, communicate the value of that opportunity, and capitalize on it. The success of the program is quantitatively demonstrated to align with the goal of raising the innovation capacity of USI graduates and the region. In an effort to increase the regional Innovation Index score to $20 \%$ by 2025 , the TCA generated employment placement of $100 \%$ of participants in positions within six months of graduation, retention of $64 \%$ of this top-tier talent in the region, and the generation of nine new entities via participants who created their own startup.

While these quantitative indicators of success are powerful, it is important to note that they are also coupled with qualitative recognition at the highest levels of the federal government and regional partners. The resulting product from the TCA is enhanced human-capital planted throughout the southwest Indiana community via shovel-ready entrepreneurs and intrapreneurs who are equipped to provide exponential return to themselves and their employers as they enter the workforce. It is clear that the long-tail impact of the 121 TCA participants involved since inception in 2012 will have a profound impact on the economic expansion of the region. 


\section{Acknowledgments}

The authors would like to thank the Lilly Endowment Initiative to Promote Opportunities Through Educational Collaborations Round III for the funding of the TCA Program. They would also like to thank mentors and coordinators that have participated in the program and have been valuable assets to teaching concepts and sharing experiences with our undergraduate students:

Jack Smothers, Jason Salstrom, Andrew Moad, Kevin Celuch, Bryan Bourdeau, Debbie Dewey, Charles Kelly, Gene Recker, and the regional community. 


\section{References}

Bezerra, É. D., Borges, C., \& Andreassi, T. (2017, 2017/10/01). Universities, local partnerships and the promotion of youth entrepreneurship. International Review of Education, 63(5), 703-724. https://doi.org/10.1007/s11159-017-9665-y

Biemiller, L. (2018). This University's 'Accelerator' Tests New Ideas for Teaching - and It's Working. The Chronicle of Higher Education.

Bogomolny, L. (2005). The Real Deal. Canadian Business, 78(6), 51-52.

Celuch, K., Bourdeau, B., \& Smothers, J. (2014). Thinking Innovatively about Teaching Innovation And Ideation: Getting Students to Think Differently. Journal of Research in Innovative Teaching, 7(1).

Christensen, C. M., Cook, S., \& Hall, T. (2005). Marketing Malpractice: The Cause and the Cure. Harvard Business Review, 83(12), 74-83.

Collet, C., \& Wyatt, D. (2005). "Bioneering" - teaching biotechnology entrepreneurship at the undergraduate level. Education + Training, 47(6), 408-421. https://doi.org/10.1108/00400910510617033

Custer, N. (2015). IN Like Flint: How the Innovation Incubator at UM-Flint Fosters Social Entrepreneurship in a City Remaking Itself. Metropolitan Universities, 26(1), 53-70.

Economic Development Coalition of Southwest Indiana. (2019). https://www.southwestindiana.org/

GAGE. (2019). Growth Alliance Greater Evansville Economic Development. https://www.growthallianceevv.com/

Garcia, S. C., \& Ustymchuk, N. (2020). Seeking Inclusion through Local Entrepreneurship Training Initiatives in Low-Income Communities. Metropolitan Universities, 31(2), 7191. https://doi.org/10.18060/23810

Gilbert, D. (2010). INTEGRATING THEORY AND PRACTICE FOR STUDENT ENTREPRENEURS: AN APPLIED LEARNING MODEL. Journal of Enterprising Culture, 18(01), 83-106. https://doi.org/10.1142/s0218495810000495

Hanna, K. A. (2013). Campus and Community Connections: The Evolving IUPUI Common Theme Project. Metropolitan Universities, 24, 60 - 69.

Heinrich, B., Yaklin, B., Goodrich, D. J., \& Knott, J. L. (2018). People, Practices, and Patterns: Transforming into a Learning Institution. Metropolitan Universities, 29(3), 85-107-185107. https://doi.org/10.18060/21469 
Innovation 2.0. (2019). Indiana Business Research Center. http://www.statsamerica.org

Johnson Jr, J. H. (2014). Public-Private Partnership, Entrepreneurship Strategy, and Regional Economic Development: A Case Study. Metropolitan Universities, 25(1), 5-38.

Jurkowski, O., \& Kerr, S. (2010). Development of an educational innovation incubator. TechTrends, 54(2), 72-77.

Klugh, E. L., \& Williams, R. C. (2017). Creating a University Driven "Ingepreneurial" Ecosystem in West Baltimore: A Strategy for Rust Belt Revitalization. Metropolitan Universities, 28(2), 103-123. https://doi.org/10.18060/21510

Knapp, J., Zeratsky, J., \& Kowitz, B. (2016). Sprint: How to Solve Big Problems and Test New Ideas in Just Five Days. Simon \& Schuster.

Luttrell, B. (2017). USI recognized for NSWC Crane partnership at Office of the Vice President. https://www.usi.edu/news/releases/2017/10/usi-recognized-for-nswc-crane-partnershipat-office-of-the-vice-president/

Ochs, J. B., Watkins, T. A., \& Boothe, B. W. (2001). Creating a truly multidisciplinary entrepreneurial educational environment. Journal of Engineering Education, 90(4), 577583. https://doi.org/10.1002/j.2168-9830.2001.tb00642.x

OPRA. (2018). 2017 Graduate Destination.

Osterwalder, A., \& Pigneur, Y. (2010). Business Model Generation: A Handbook for Visionaries, Game Changers, and Challengers. John Wiley \& Sons, Inc.

Tekula, R., \& Jhamb, J. (2015). Universities as intermediaries: Impact investing and social entrepreneurship. Metropolitan Universities, 26(1), 35-52.

Thompson, D. (2012). Accelerating the growth of the next generation of innovators. Ohio State Entrepreneurial Business Law Journal, 8, 379 - 391.

Woods, S., Reed, B., \& Smith-Howell, D. (2016). Building an engagement center through love of place: The story of the Barbara Weitz Community Engagement Center. Metropolitan Universities, 27(3), 84-105. 


\section{Supplementary Material}

\section{Supplemental Figure 1. Student Application for TCA Program.}

\section{Student information}

First name

Last name

USI email

Major(s)

Minor(s)

Current GPA

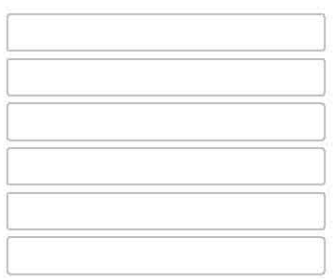

Class standing

Freshman

Sophomore

Junior

Senior

Graduate school

Are you a U.S. Citizen?
Yes
No

Have you participated at any level in these innovative or entrepreneurial programs?

Eagle Innovation Accelerator

$\square$ APPCOM

$\square$ BIZCOM

$\square$ Entrepreneurship Minor

$\square$ SCORE

$\square$ Purdue Foundry

$\square$ Tech on Tap

$\square$ Indiana Small Business Development Center

$\square$ Growth Alliance for Greater Evansville 
Describe what motivates you and how you demonstrate initiative?

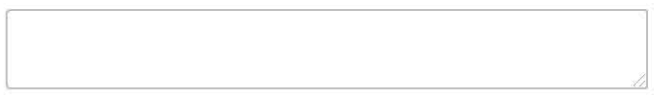

What are your plans following graduation?

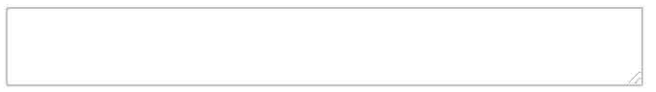

What motivated you to apply to the TCA?

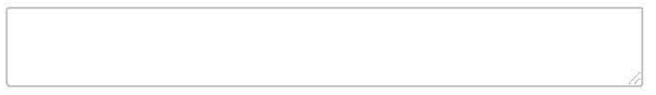

What makes you unique and how do you believe that will benefit the TCA?

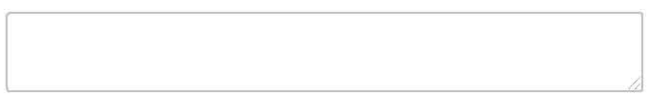

What USI faculty (i.e. Professors, advisors, etc.) or work supervisor could speak as a reference for you?

First name

Last name

Email

Phone

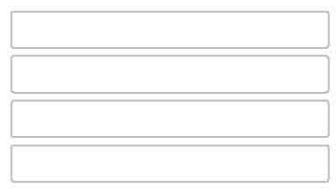

Do you have an idea that could benefit from being worked on during the TCA? If so, please describe the idea in detail (Note: All submissions will be restricted to a need-to-know basis for candidate evaluation).

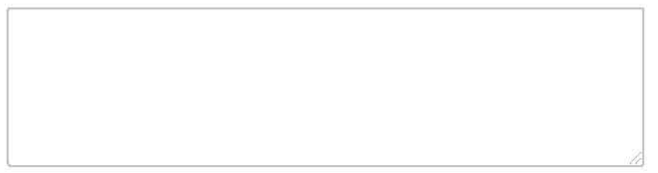

Why should we select you to be one of the 16 students taken? 


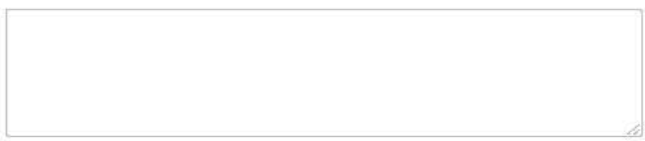

Answer one of the following:

Describe how would you determine the size of the market (number of potential users) for the fall semester at USI for a calculus tutoring mobile app?

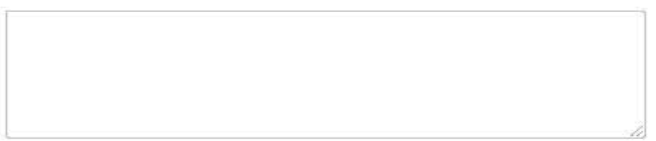

What design media (e.g. which software) are you comfortable working in? Describe your design process (if any).

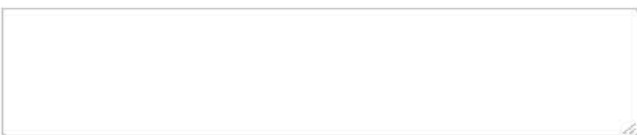

Click to write the question text

im not a robot

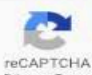

Powered by Qualtrics 
Supplemental Figure 2. Business Model Canvas (Osterwalder \& Pigneur, 2010).

The Business Model Canvas

Designed for:

Date:

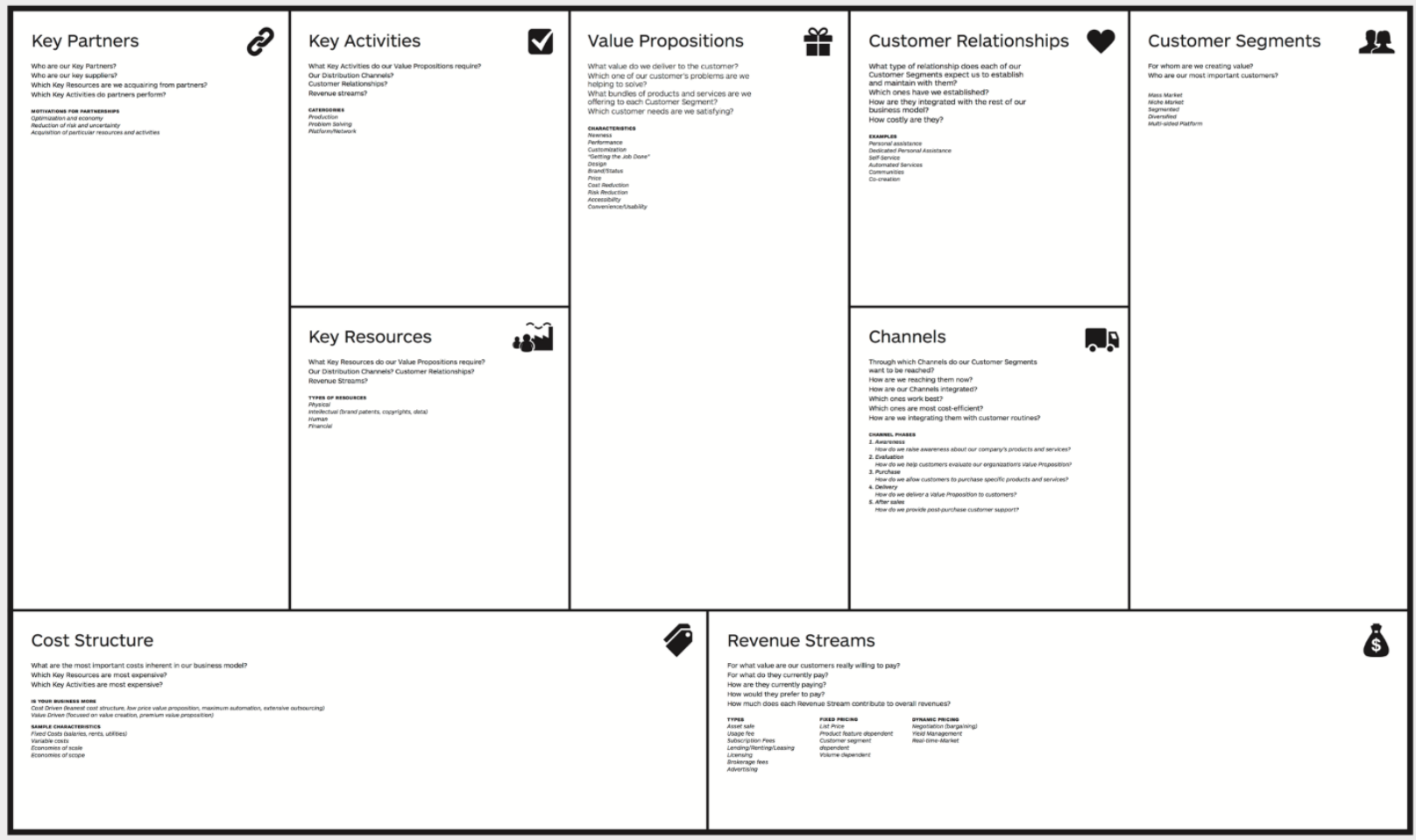

(C) The Author 2021. Published by the Coalition of Urban and Metropolitan Universities. www.cumuonline.org 